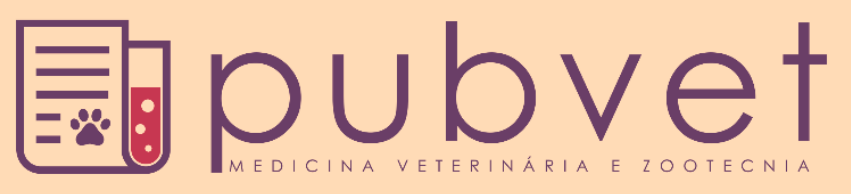

https://doi.org/10.31533/pubvet.v14n11a690.1-11

\title{
Aspectos epidemiológicos, clínico-patológicos e diagnóstico de raiva em animais de produção: Revisão
}

\author{
Lucas de Souza Quevedo $^{1 * \mathscr{G}}$, Gustavo Gois Padilha Hugen ${ }^{1}$, Raissa Moreira de Morais ${ }^{1}$, Pedro de \\ Souza Quevedo 29
}

${ }^{1}$ Laboratório de Patologia Animal, Departamento de Medicina Veterinária, Centro de Ciências Agroveterinárias (CAV), Universidade do Estado de Santa Catarina (UDESC), Av. Luiz de Camões 2090, Bairro Conta Dinheiro, Lages, SC, Brasil.

${ }^{2}$ Centro de Diagnóstico e Estudos em Parasitologia Animal, Instituto de Estudos do Trópico Úmido (IETU), Universidade Federal do Sul e Sudeste do Pará (UNIFESSPA), Rua Santos Dumont S/N, Bairro Jardim Universitário, Xinguara, PA, Brasil.

*Autor para correspondência, E-mail: souzaquevedo@gmail.com

Resumo. A raiva é uma enfermidade viral que acomete animais silvestres e domésticos relatada no Brasil desde 1911. Sob o ponto de vista de saúde pública, é imperativo que pessoas que tenham contato com animais sejam submetidas a vacinação. $O$ vírus da raiva é neurotrópico e altamente letal a humanos e animais. Os prejuízos inerentes a raiva são de difícil quantificação e a cadeia produtiva de bovinos é a mais afetada. O presente trabalho aborda de maneira sucinta aspectos etiológicos da raiva, bem como fatores epidemiológicos envolvidos na manutenção da enfermidade em sistemas produtivos e, no meio silvestre e urbano. Os sinais clínicos em animais acometidos pela enfermidade foram elencados conforme as espécies e formas clínicas de apresentação da raiva, a saber, paralítica e furiosa. Também foram abordados tópicos sobre as principais alterações de necropsia, lesões histopatológicas da enfermidade com algumas peculiaridades referentes a distribuição e características das lesões. Foram listadas as principais formas de diagnóstico da raiva em animais de produção e medidas de controle e profilaxia.

Palavras chave: corpúsculo de Negri, sistema nervoso central, Desmodus rotundus

\section{Epidemiological, clinical-pathological aspects and rabies diagnosis in farm animals: Review}

\begin{abstract}
Rabies is a viral disease that affects wild and domestic animals has been reported in Brazil since 1911. From the point of view of public health, it is imperative that people who have contact with animals be subjected to vaccination. The rabies virus is neurotropic and highly lethal to humans and animals. The damage inherent to rabies is difficult to quantify and the livestock production chain is the most affected. This paper briefly addresses the etiological aspects of rabies, as well as epidemiological factors involved in maintaining the disease in productive systems and the wild and urban environments. The clinical signs in animals affected by the disease were listed according to the species and clinical forms of presentation of rabies, namely, paralytic and furious. Topics on the main necropsy changes, histopathological lesions of the disease were also addressed, with some peculiarities regarding the distribution and characteristics of the lesions. The main forms of rabies diagnosis in farm animals and measures of control and prophylaxis were listed.
\end{abstract}

Keywords: Negri corpuscle, central nervous system, Desmodus rotundus

\section{Introdução}

A raiva é uma importante doença viral geralmente transmitida através da inoculação do vírus por morcegos hematófagos (Desmodus rotundus) (Verdes et al., 2016). O vírus pertence à família 
Rhabdoviridae e gênero Lyssavirus e tem como reservatórios diferentes mamíferos (Picard-Meyer et al., 2019). A doença é uma zoonose e causa grandes prejuízos devido a mortalidades em rebanhos bovinos, equinos, caprinos e ovinos (Allen et al., 2013; Filho et al., 2016; Marcolongo-Pereira et al., 2011; Verdes et al., 2016).

A raiva é caracterizada por lesões neurológicas e tem como lesão patognomônica a menigoencefalite não-supurativa associada a corpúsculos de inclusão viral eosinofílicos intracitoplasmáticos, conhecidos como Corpúsculos de Negri, estes que não são encontrados em 30\% dos casos (Langohr et al., 2003). A idade dos indivíduos acometidos é irrelevante, pois qualquer animal pode desenvolver o quadro desde que ocorra inoculação do vírus por um animal raivoso ou contaminação em soluções de continuidade recentes por saliva de animais portadores do vírus ou contato com mucosas (olhos, narinas e boca) (Fernandes \& Riet-Correa, 2007; Peixoto, 1998; Verdes et al., 2016).

Este estudo tem como objetivo realizar uma revisão de literatura com abrangência dos aspetos epidemiológicos, sinais clínicos e formas de diagnóstico da raiva em animais de produção.

\section{Etiologia e patogenia}

A raiva é causada por um vírus RNA de aproximadamente $11 \mathrm{~Kb}$ de tamanho, pertence a ordem Mononegavirales, família Rhabdoviridae do gênero Lyssavirus, a qual, possui 16 espécies (PicardMeyer et al., 2019). É envelopado, apresenta "formato de bala", $180 \mathrm{~nm}$ de comprimento e $75 \mathrm{~nm}$ de largura (SIB, 2020). O vírus da raiva (VRA), possui ampla diversidade genética e depende principalmente do hospedeiro e da origem geográfica (Picard-Meyer et al., 2019).

No Brasil, o VRA possui sete caracterizações antigênicas $(\mathrm{AgV})$, duas em cães (AgV1 - Canis familiaris e AgV2 - Canis familiaris), três em morcegos (AgV3 - Desmodus rotundus; AgV4 - Tadarida brasiliensis e AgV6 - Lasiurus spp.) e duas em reservatórios silvestres, Cerdocyon thous (AgV2*) e Callithrix jacchus (AgVCN) (BRASIL, 2016)

De acordo com a Organização Mundial da Saúde (OMS) anualmente morrem aproximadamente 59.000 pessoas em 150 países, com 95\% dos casos concentrados na África e Ásia. Este número é subestimado pois há subnotificação e estimativa incerta. Cabe ressaltar que $99 \%$ dos casos humanos ocorrem após ataques de cães e, aproximadamente metade dos casos ocorrem em crianças e adolescentes de até 15 anos (WHO et al., 2019). O VRA causa uma encefalite progressiva fatal e possui duas formas clínicas bem características, a forma furiosa a qual cursa com hiperatividade e alucinações, e a forma paralítica caracterizada por paralisia e coma (Picard-Meyer et al., 2019; WHO et al., 2019).

A patogênese da doença inicia com o animal raivoso (morcego, cão, etc), que inocula o vírus da raiva através da mordedura ou lambedura (Filho et al., 2016). O vírus que está na saliva deste animal se replica nas células musculares do animal que foi inoculado e progride aos terminais dos axônios motores e fusos neuromusculares (Fernandes \& Riet-Correa, 2007).

Ao ser inoculado no organismo do animal, o vírus realiza ligação de suas glicoproteínas G aos receptores do hospedeiro mediadas por Clatrina (proteína que desempenha importante papel na formação de vesículas) na célula hospedeira. Logo, ocorre fusão da membrana do vírus com a membrana da vesícula e o ribonucleocapsídeo é liberado no citoplasma; seguida de transcrição sequencial dos mRNAs virais que são limitados e poliadenilados. Ocorre então replicação após haver nucleoproteína suficiente para encapsular antígenomas e genomas neo-sintetizados. O ribonucleocapsídeo é ligado com a proteína da matriz e brota por meio do complexo de classificação endossômica necessário para o transporte (ESCRT) do hospedeiro localizados na membrana plasmática, liberando novos virions ( $\underline{\text { SIB, 2020) }}$.

Ocorre uma ascensão por fluxo axonal plasmático retrógrado até a medula espinhal ou tronco encefálico. A partir do encéfalo e da medula espinhal há disseminação centrífuga ao longo dos nervos periféricos para vários órgãos. O vírus se replica nas células epiteliais dos ácinos das glândulas salivares, extravasa para o lúmen e é eliminado pela saliva do animal infectado (Fernandes \& Riet-Correa, 2007).

O período de incubação geralmente é de 2-3 semanas de acordo com a OMS (2020), mas pode variar de uma semana a um ano dependendo da localização da inoculação e da carga viral inoculada e a evolução do quadro clínico é de 1-2 dias, porém pode se estender por até 8-10 dias (Fernandes \& RietCorrea, 2007). 


\section{Epidemiologia}

Estima-se que a raiva cause um impacto econômico de aproximadamente US \$ 8,6 bilhões anuais em todo o mundo, sendo destes, $6 \%$ referentes a perdas em rebanhos bovinos (FAO, 2017). No Brasil alguns estudos fazem estimativas das perdas econômicas em decorrência da raiva bovina, apontando a morte de aproximadamente 842.688 cabeças, reforçando a importância da doença que é descrita no país desde 1911 (Carini, 1911; Lima et al., 2005; Mello et al., 2019). A partir de 1966 foi implantado o Plano de Combate a Raiva dos Herbívoros que hoje é conhecido como Programa Nacional de Controle da Raiva dos Herbívoros e Outras Encefalopatias (PNCRH) (BRASIL, 2009).

Desde que foi descrito o ciclo do vírus da raiva, a enfermidade passou a ser alvo de diversos estudos epidemiológicos, muitos destes direcionados à dinâmica populacional e demais aspectos da biologia dos morcegos hematófagos, protagonistas na transmissão do vírus. Devido a disputa dos morcegos machos pelas fêmeas na primavera, e após as agressões que sofrem de outros morcegos, estes procuram novas colônias carreando o vírus e transmitindo a estas novas colônias. Considerando o período de incubação nos morcegos, o aparecimento dos sinais clínicos em bovinos provavelmente ocorrerá no outono (Fernandes \& Riet-Correa, 2007).

Outros animais também podem transmitir o vírus, como cães, lobos, raposas dentre outros, mas atualmente, os principais transmissores no Brasil são os morcegos hematófagos (Desmodus rotundus) (Feng et al., 2015; Verdes et al., 2016; Zhu et al., 2011). Cumpre salientar que os cães já foram considerados importantes transmissores no país antes da década de 80 e, devido a medidas de controle com vacinações à raiva, nesta espécie a enfermidade tem sido pouco diagnosticada atualmente (Belotto et al., 2005; Lima et al., 2005).

Em ovinos a raiva é considerada uma doença de menor frequência e três fatores podem explicar essa baixa ocorrência no Brasil: o primeiro é o controle da raiva urbana na década de 1980 o que influenciou no controle da raiva canina e consequentemente os ovinos atacados por cães passaram a não mais desenvolver a doença; segundo fator é a aparente preferência dos morcegos por bovinos, quando comparado com os ovinos (Belotto et al., 2005; Lima et al., 2005; Zhu et al., 2011); e terceiro a lã espessa que dificulta a chegada e ação dos morcegos (Rissi et al., 2008).

Em equinos a raiva cursa na forma paralítica e, assim como nos bovinos da América do Sul, a maior parte dos casos é transmitida por morcegos hematófagos (Desmodus rotundus) (Bassuino et al., 2016; Pedroso et al., 2010; Wright \& Greene, 2016).

Em suínos, a epidemiologia da raiva está associada com ataques de cães em países da África e Ásia e até mesmo no Brasil, entretanto, no país há relato da raiva transmitida por morcegos hematófagos (Jiang et al., 2008; Nair \& Jayson, 2020; Pessoa et al., 2011).

De acordo com Rech et al. (2004), a maior incidência de raiva bovina ocorre na primavera e verão, forma que é considerada a raiva selvagem (rural), que é isolada de morcegos e animais de produção. A outra variante está associada ao ciclo urbano e geralmente isolada de cães, gatos e humanos (Heinemann et al., 2002; Ito et al., 2001). Outros ciclos também são sugeridos como o silvestre, que ocorre entre animais silvestres como raposas, guaxinins, gambás e primatas, e a transmissão pode ser intra ou interespécies. De forma alternativa o ciclo aéreo, na qual, ocorre transmissão do vírus entre morcegos hematófagos, frugívoros e insetívoros é considerada importante para a manutenção do vírus entre as espécies de morcegos (Fernandes \& Riet-Correa, 2007).

A raiva urbana é de grande importância devido a consequências que ela pode causar na população. No Rio Grande do Sul, o ciclo urbano foi controlado na década de 1980 (Rissi et al., 2008), este fato provavelmente ocorreu devido a campanhas de vacinações que foram intensificadas nesta época. Devese considerar que a morbidade da raiva em rebanhos bovinos pode variar de $0,04 \%$ a $20 \%$ e a letalidade de 100\% (Mello et al., 2019).

\section{Sinais clínicos}

Como na maioria dos casos documentados no Brasil, a doença geralmente é manifestada na forma paralítica, entretanto há uma forma furiosa que também é relatada em bovinos (Langohr et al., 2003; Marcolongo-Pereira et al., 2011). O curso clínico em bovinos varia de três a quatorze dias, e os sinais 
apresentados na forma paralítica são caracterizados por apatia ou inquietação, mudança no comportamento, incoordenação motora, paresia e paralisia inicial dos membros pélvicos, decúbito, depressão, movimentos de pedalagem, sialorreia, opistótono seguida de morte (Figura 1A) (Marcolongo-Pereira et al., 2011; Terra et al., 2018).

Salienta-se que, alguns animais podem apresentar a forma furiosa da doença que é caracterizada por agressividade e mugidos frequentes, com relatos de prurido intenso (Langohr et al., 2003). De acordo com Fernandes \& Riet-Correa (2007), a forma furiosa é mais comum em cães e geralmente está relacionada a lesões cerebrais e a forma paralítica a lesões da medula, tronco encefálico e é mais frequente em herbívoros.

Lima et al. (2005) realizaram um levantamento na região Nordeste do Brasil que constatou que a evolução clínica em bovinos e equinos variou de 2 a 8 dias, em ovinos de 3 a 5 dias e em um caso diagnosticado em caprino foi de 35 dias, o que chama a atenção por este tempo ser até 17 vezes maior que em bovinos e equinos, em determinadas situações ( 2 dias de evolução). Ainda neste estudo é citado que o quadro mais característico na espécie bovina é a forma paralítica progressiva e as lesões preferentemente medulares e com comprometimento variável de tronco encefálico; em equinos a principal característica foi a evidência de lesões difusas no SNC, pois afetou medula, tronco e cerebelo; em ovinos os sinais clínicos são mais voltados a lesões em medula e tronco encefálico assim como nos caprinos, porém nesta última espécie também pode ser observado sinais clínicos voltados a lesões cerebrais e cerebelares.

Nos equinos, os primeiros sinais são depressão, perda do apetite, claudicação e sinais de cólica, posteriormente paralisia facial, salivação excessiva, incapacidade de engolir, espasmos repetitivos, hipersensibilidade ao toque, coceira, automutilação, mudança no comportamento, como agressividade e ansiedade, fotofobia, hipermetria e dismetria, debilidade de membros, incoordenação motora, paralisia de membros pélvicos, paralisia de cauda, perda no tônus da língua seguida de morte (Pedroso et al., 2010; Tolouei \& Mostofi, 2017; Wright \& Greene, 2016).

Em ovinos, os sinais clínicos variam de dois a quinze dias e são caracterizados por apatia, incoordenação dos membros pélvicos, tremores musculares, decúbito lateral prolongado, movimentos de pedalagem, convulsões e opistótono seguidos de morte (Filho et al., 2016; Rissi et al., 2008).

Os suínos podem apresentar sinais em aproximadamente dez dias após a inoculação do vírus e caracterizam-se por anorexia, paresia seguida de paralisia flácida dos membros pélvicos e cauda, postura de cão sentado, seguida de decúbito lateral, alguns suínos desenvolvem agressividade e acabam mordendo uns aos outros. É relatado também hiperexcitação, grunhidos, espasmos em resposta a estímulos táteis, auditivos e visuais (Jiang et al., 2008; Nair \& Jayson, 2020; Pessoa et al., 2011).

\section{Diagnóstico}

O diagnóstico de raiva não pode ser baseado apenas em aspectos clínicos, principalmente porque os sinais clínicos podem ser inespecíficos e podem variar entre as espécies e até em indivíduos da mesma espécie.

Associado ao exame clínico é fundamental a análise da situação epidemiológica no local, a história da infecção na região, a presença de morcegos hematófagos e a possibilidade da introdução de animais provenientes de áreas endêmicas. A associação desses dados permitirá um diagnóstico presuntivo, que deve ser confirmado por testes laboratoriais (Rodriguez et al., 2007).

O diagnóstico laboratorial de raiva nas diversas espécies de animais de produção é realizado prioritariamente pelo método da imunofluorescência direta em tecido cerebral, seguido pelo teste da inoculação em camundongo, que altamente sensível e fácil de ser executado, porém, o tempo para obtenção dos resultados é um limitante da técnica, o resultado demora em média 21 a 30 dias. Quando se observa a questão ética da utilização de animais em testes, percebemos que em algumas situações opta-se pelo isolamento viral (Kanitz et al., 2015).

Outras técnicas como a histopatologia e a imunohistoquímica também pode ser utilizada. Para tal, é necessária que seja realizada a necropsia para obtenção de amostras de tecido nervoso. Os materiais de 
escolha para aplicação destas técnicas são hipocampo, tronco cerebral, tálamo, córtex, cerebelo, medula oblonga e medula espinhal (BRASIL, 2009).

Em algumas situações, por limitações técnicas ou estruturais, não é possível coletar o material do sistema nervoso central. Nestes casos é possível enviar a cabeça do animal inteira para um laboratório referência, mantida sob refrigeração ou imersa no Líquido de Vallée (glicerina 50\% tamponada com tampão fosfato). Esta solução permite que o vírus permaneça detectável por vários dias. É importante tomar todos os cuidados necessários bem como utilizar equipamentos de proteção individual para evitar inoculação e exposição acidental ao vírus (Batista et al., 2007).

\section{Alterações macroscópicas}

Alguns achados de necropsia como hiperemia dos vasos encefálicos, bexiga distendida por urina e conteúdo ressequido no trato gastrointestinal são frequentemente encontrados e considerados sugestivos para raiva (igura 1B) (Bassuino et al., 2016; Bianchi et al., 2017; Casagrande et al., 2012; Langohr et al., 2003; Lima et al., 2005).

Há casos em que é evidente a região de sugadura do morcego (Casagrande et al., 2012) e escoriações nas regiões dos membros torácicos, pélvicos e cabeça (Lima et al., 2005; Pedroso et al., 2010).

Em equinos e bovinos, observam-se ainda áreas de hemorragias multifocais em substância cinzenta da medula espinhal (Bassuino et al., 2016; Langohr et al., 2003; Pedroso et al., 2010). De acordo com Abd El Rahman et al. (2015), em búfalos, além da hiperemia de meninge, observou-se também áreas de hemorragia com alargamento dos giros em hemisfério cerebral, edema do cerebelo, congestão e edema grave em ventrículo lateral.

\section{Histopatologia}

Os achados microscópicos em animais positivos para raiva são limitados ao sistema nervoso central e podem variar de acordo com a evolução clínica (Lima et al., 2005). Frequentemente as lesões são observadas no tronco encefálico, cerebelo, medula espinhal, hipotálamo e gânglios trigeminais (Bassuino et al., 2016; Langohr et al., 2003; Rissi et al., 2008).

Microscopicamente, a raiva caracteriza-se por meningoencefalite e meningomielite não-supurativa associado a corpúsculos de inclusão intracitoplasmáticos eosinofílicos (Corpúsculo de Negri) (Figura $\underline{1 C}$ e D) (Bassuino et al., 2016; Filho et al., 2016; Pessoa et al., 2011; Siepker et al., 2020). Em meninge e neuroparênquima observa-se infiltrado inflamatório mononuclear e infiltrado perivascular (manguitos perivasculares) constituídas por linfócitos, plasmócitos e macrófagos, que variam em número de camadas (Bassuino et al., 2016; Bianchi et al., 2017; Langohr et al., 2003).

Degeneração e necrose neuronal também são observados em animais acometidos por essa enfermidade (Abd El Rahman et al., 2015; Bassuino et al., 2016; Rissi et al., 2008). Em um estudo no qual se avaliou 25 amostras de sistema nervoso de bovinos positivos para raiva, um grande número de neurônios necróticos com grau de lesão variável de leve a moderada foram observados em neurônios de Purkinje no cerebelo, células piramidais do hipocampo e núcleos do tronco encefálico e substância cinzenta do medula espinhal (Langohr et al., 2003).

Outras lesões microscópicas observadas frequentemente na raiva é a presença de cromatólise central, microgliose nodular e neuronofagia (Bassuino et al., 2016; Bianchi et al., 2017; Siepker et al., 2020). Alterações como rarefação do neurópilo, esferoides axonais e infiltração por "Gitter cells" (malácia) foram observadas em medula espinhal de ovinos (Rissi et al., 2008). Em equinos as lesões histológicas de raiva são mais evidentes em medula espinhal. Em um estudo no qual caracterizou-se as lesões microscópicas de raiva em medula espinhal de equinos, constatou-se que lesões medulares estavam presentes em todos os casos avaliados e que a chance de detectar lesões é 3,5 vezes maiores quando avaliam seções de medula espinhal em comparação com análise de amostras cerebrais isoladamente (Bassuino et al., 2016).

Inclusões intracitoplasmáticas eosinofílicas (Corpúsculo de Negri) com diferentes tamanhos são observados em citoplasmas neuronais de grande parte dos animais com a enfermidade. Grandes neurônios são os locais mais frequentes onde se observa esse tipo de alteração, como neurônios de 
Purkinje no cerebelo, neurônios do tronco encefálico e da medula espinhal (Bassuino et al., 2016; Bianchi et al., 2017; Lima et al., 2005; Marcolongo-Pereira et al., 2011). Normalmente, nessa enfermidade a quantidade de corpúsculos de Negri apresenta-se maior em áreas com menor grau de lesões (Langohr et al., 2003; Lima et al., 2005; Rissi et al., 2008). Em suínos não é observado corpúsculos de Negri (Pessoa et al., 2011; Siepker et al., 2020).

Ganglioneurite e neuroipofisite não-supurativa também é descrito em animais acometidos pela raiva (Bianchi et al., 2017; Casagrande et al., 2012; Pessoa et al., 2011; Rissi et al., 2008). De acordo com Rech et al. (2004) em um estudo onde avaliou-se 21 tecidos de gânglio de Gasser, rete mirabile carotídea e hipófise de bovinos com diagnóstico de raiva as principais lesões microscópicas observadas foram cromatólise central, necrose neuronal, neuronofagia, proliferação de células satélite (nódulos de Babe), formação de Corpúsculos de Negri e vacuolização citoplasmática neuronal.

Congestão vascular, hemorragia (Abd El Rahman et al., 2015; Feng et al., 2015; Pedroso et al., 2010; Terra et al., 2018) e tumefação endotelial (Rissi et al., 2008) podem ser observados em amostras de encéfalo e medula espinhal de animais com raiva.

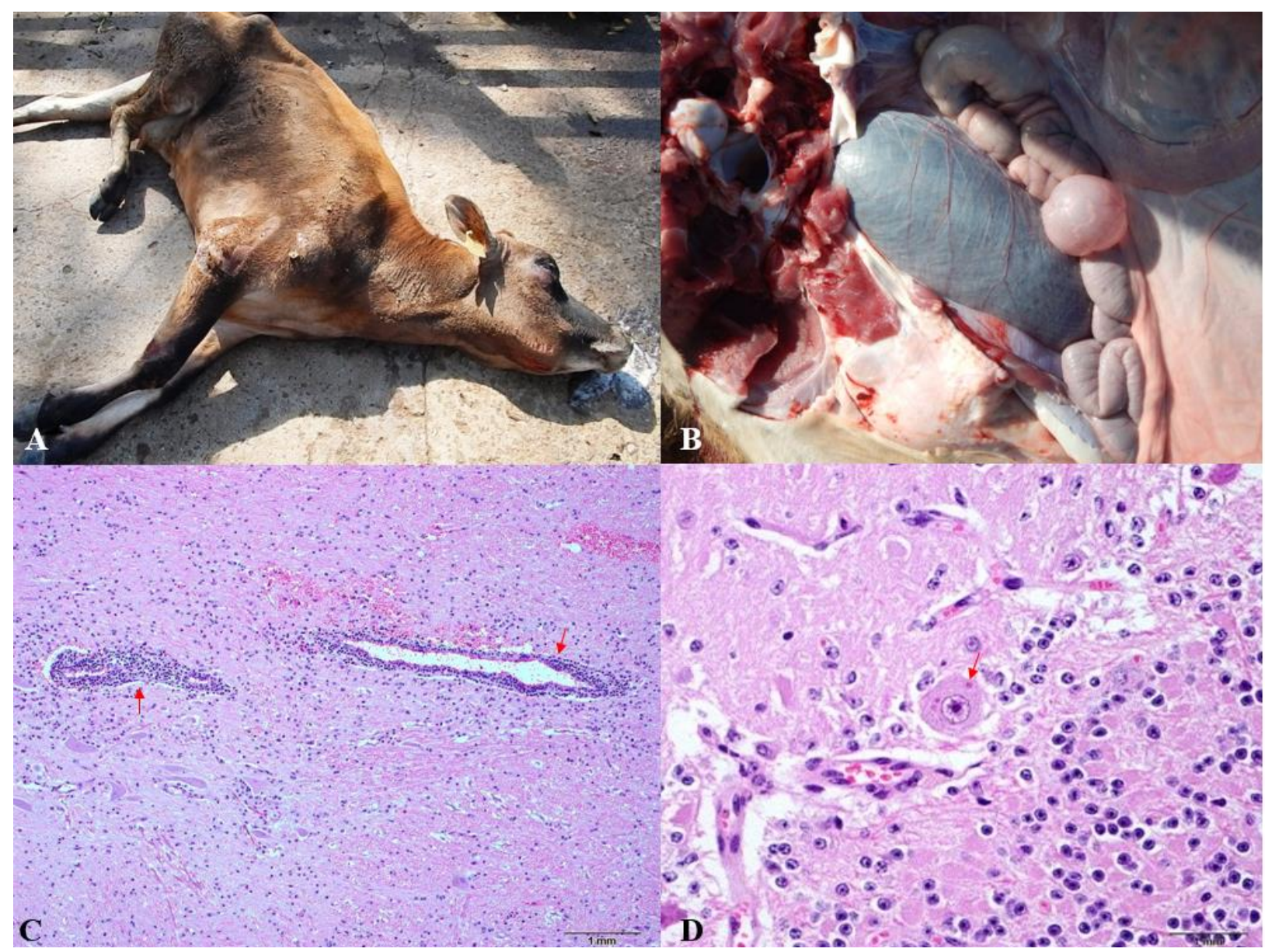

Figura 1. Bovino com diagóstico positivo para raiva. (A). Bovino com posição de opistótono e salivação excessiva. (B). observa-se vesícula urinária distendida por urina. (C). Sistema Nervoso Central. Observa-se infiltrado inflamatório mononuclear perivascular moderado (manguito perivascular) (setas vermelhas). Em neurópilo oberva-se infiltrado inflamatório mononuclar moderado, difuso associado a neuronofagia e hemorragia multifocal, moderado. (D). Sistema Nervoso Central (cerebelo). Observa-se em neurônio de Purkinje corpúsculos intracitoplasmáticos eosinofílicos (Corpúsculos de Negri) (seta vermelha).

\section{Imunohistoquímica}

Na imunohistoquímica os antígenos específicos do agente a ser pesquisados marcam o anticorpo, é um teste útil quando não se pode refrigerar ou acondicionar a amostra em soluções de transporte, pois pode ser realizado em material fixado em formol. A sensibilidade e especificidade são altas, próximas a 100\% (Pedroso et al., 2009). 


\section{Imunofluorescência direta}

Este teste é considerado oficial pelo Ministério da Agricultura Pecuária e Abastecimento - MAPA, constante no Programa Nacional de Controle de Raiva em Herbívoros (PNCRH), sendo recomendado pela OMS - Organização Mundial da Saúde e pela OIE - Organização Mundial de Saúde Animal (BRASIL, 2009).

A imunofluorescência direta em tecidos congelados e/ou refrigerados é a técnica de escolha para diagnóstico de raiva pela sua acurácia e rapidez. A técnica baseia-se em impressões de tecido fresco em lâminas de microscopia e seu resultado é obtido em poucas horas, a sensibilidade e especificidade são próximas a 100\% (Langohr et al., 2003).

Para execução da técnica, são necessárias amostras frescas refrigeradas, o que pode inviabilizar a execução a campo ou quando o laboratório está distante da propriedade, porém, pode-se executá-la a partir de amostras conservadas em glicerina (BRASIL, 2009).

\section{Isolamento viral}

No isolamento viral é realizada a inoculação da suspensão de tecidos extraídos da amostra coletada em sistemas biológicos. Este teste é utilizado em conjunto com a imunofluorescência direta, conforme recomendação da OMS (BRASIL, 2009).

Como alternativa para reduzir o número de animais para diagnóstico, pode-se realizar a inoculação em cultivos celulares ao invés de camundongos. As células baby hamster kidney (BHK) e as células de neuroblastomas (N2A) são as mais utilizadas, embora diversas linhagens celulares sejam susceptíveis ao vírus da raiva (Rodriguez et al., 2007).

Segundo Kanitz et al. (2015), o isolamento viral nas células BHK e N2A demonstrou sensibilidade e especificidade de $100 \%$, detectando inclusive amostras negativas à imunofluorescência direta.

\section{Diagnóstico diferencial}

Diversas doenças nas quais os animais desenvolvem sinais clínicos nervosos podem ser consideradas no diagnóstico diferencial da raiva em animais de produção. Enfermidades que acometem primeiramente o sistema nervoso central como meningoencefalite por herpesvírus bovino tipo 5 (BHV5), febre catarral maligna, encefalopatia espongiforme bovina (BSE), listeriose, botulismo e tétano são os principais exemplos de enfermidades de origem infecciosa (Rech et al., 2004; Sanches et al., 2000). Babesiose cerebral causada por Babesia bovis é umas das enfermidades que acometem o SNC de bovinos e torna-se uma das principais doenças como diagnóstico diferencial (Oliveira et al., 2018).

Enfermidades primárias do SNC de origem tóxica também são descritas como possíveis diagnósticos diferenciais de raiva, dentre elas intoxicações por plantas que causam doença do armazenamento lisossomal e tremorgênicas (Morais et al., 2019), intoxicação por chumbo (Lemos et al., 2004) e organofosforado (Santos et al., 2014).

Intoxicações por plantas hepatotóxicas (Senecio spp. Crotalaria spp.) devem ser consideradas no diagnóstico diferencial (Claus et al., 2002; Rech et al., 2004; Sanches et al., 2000). No caso das intoxicações por plantas hepatotóxicas, o diagnóstico diferencial pode ser realizado através de biópsia hepática (Fernandes \& Riet-Correa, 2007). As lesões observadas na histopatologia permitem a diferenciação da maioria das enfermidades citadas, ao contrário acontece no botulismo e tétano que não apresentam lesões nem macroscópicas nem microscópica, tornando os dados epidemiológicos fundamentais para o diagnóstico diferencial (Fernandes \& Riet-Correa, 2007).

\section{Controle e profilaxia}

A principal ferramenta de controle da raiva é a vacinação dos animais susceptíveis, nas áreas endêmicas e pelo controle das populações de morcegos hematófagos (Rodriguez et al., 2007).

O MAPA é o órgão governamental responsável pela normatização, coordenação e supervisão das ações do Programa Nacional de Controle de Raiva dos Herbívoros. Através deste programa são definidas 
as estratégias para controle e prevenção da doença, bem como do credenciamento dos laboratórios de diagnóstico. As Superintendências Federais de Agricultura coordenam e supervisionam as atividades de controle nas Unidades da Federação. Em cada Superintendência existe um Serviço de Defesa Sanitária Agropecuária, este Serviço é o responsável por executar as ações do Programa Nacional, como monitoramento de furnas e abrigos de morcegos hematófagos, cadastramento de propriedades rurais, vigilância em áreas e propriedades de risco e atendimento em locais com foco da doença.

Somado a isto, o Serviço de Defesa Sanitária Agropecuária também é responsável por realizar ações educativas, participar em comitês municipais de sanidade animal, capacitar recursos humanos, fiscalizar e vacina rebanhos, além de fornecer informações ao MAPA sobre as ações executadas (BRASIL, 2009).

Em caso de confirmação de diagnósticos positivos por meio laboratorial, os laboratórios credenciados devem informar imediatamente aos órgãos competentes e encaminhar as amostras negativas para diagnóstico diferencial (BRASIL, 2009).

A raiva é uma doença de notificação compulsória, sendo que é de responsabilidade do Médico Veterinário e/ou proprietário notificar o serviço veterinária oficial, toda vez que houver suspeita da doença, bem como em casos de mordidas de morcegos hematófagos (BRASIL, 2009).

O PNCRH é norteado pelo monitoramento epidemiológico, orientação à vacinação de herbívoros domésticos e controle de morcegos hematófagos. O monitoramento epidemiológico é realizado a partir da identificação de áreas de risco (BRASIL, 2009).

A vacinação é realizada de maneira profilática, na dose de $2 \mathrm{~mL}$ por animal, com vírus inativado, independentemente da idade, por via subcutânea ou intramuscular. Nas áreas endêmicas, a vacinação deve ser sistemática, em bovídeos e equídeos, a partir de 90 dias de idade, sendo aplicada em duas doses, com intervalo de 30 dias e reforço anual. Em áreas de ocorrência de raiva, a vacina deve ser sistemática em bovídeos e equídeos com idade superior ou igual a três meses, deve-se aplicar duas doses com intervalo de 30 dias e reforço anual (BRASIL, 2009). A vacinação é uma medida de prevenção que tem por objetivo interromper a transmissão entre os animais domésticos e selvagens (Oliveira et al., 2000).

Para controle das populações de morcegos hematófagos, principalmente o Desmodus rotundus, são utilizados métodos baseados na aplicação de pastas à base de substâncias anticoagulantes, principalmente warfarina (Batista et al., 2007; BRASIL, 2009).

Existem dois métodos de controle: seletivo indireto e direto. No método seletivo indireto, a pasta anticoagulante é aplicada próxima às mordeduras. Este método é menos efetivo que o direto pois elimina apenas o morcego agressor. No caso do método seletivo direto é necessário que seja realizada a captura dos morcegos próximo aos abrigos e/ou áreas de alimentação, porém, para realizar esta captura é necessária autorização do Instituto Brasileiro do Meio Ambiente e dos Recursos Naturais Renováveis (IBAMA). Aplica-se pasta anticoagulante nos morcegos capturados, que quando retornam à colônia, devido ao hábito de higiene mútua, transferem a pasta aos outros morcegos da colônia. O método seletivo direto só pode ser executado pelo Serviço Oficial (BRASIL, 2009).

\section{Considerações finais}

O Brasil atualmente é protagonista mundial na produção de grãos e proteína animal. Nesse sentido, os animais de produção representam os esteios que permitem ao país ostentar lugar de destaque, entre os mercados de carne e leite, por exemplo. Enfermidades que impactem nos desempenhos e índices produtivos devem ser veementemente combatidas, visto que as exigências produtivas atentam cada vez mais para fatores ambientais e níveis produtivos elevados. Essas condições não permitem aos pecuaristas expandir áreas de pasto para aumentar a produção de carne bovina, por exemplo. Em contrapartida, as áreas destinadas às lavouras são cada vez maiores e seus lucros alavancam a atividade agrícola, restando aos criadores de animais produzir o mesmo ou mais, em áreas proporcionalmente menores.

A raiva, além de representar um severo risco a integridade dos rebanhos requer atenção por ser letal aos humanos. Dessa forma, toda e qualquer medida de controle e profilaxia, bem como esclarecimentos técnicos aos suscetíveis devem ser adotadas de maneira impreterível. 


\section{Referências bibliográficas}

Abd El Rahman, S., Elbeskawy, M., \& Hamed, M. F. (2015). Detection of Rabies virus and its pathological changes in brain of buffaloes in Egypt. Advances in Animal and Veterinary Sciences, 3(11), 588-593.

Allen, A. L., Goupil, B. A., \& Valentine, B. A. (2013). A retrospective study of brain lesions in goats submitted to three veterinary diagnostic laboratories. Journal of Veterinary Diagnostic Investigation, 25(4), 482-489. https://doi.org/10.1177/1040638713493627

Bassuino, D. M., Konradt, G., Cruz, R. A. S., Silva, G. S., Gomes, D. C., Pavarini, S. P., \& Driemeier, D. (2016). Characterization of spinal cord lesions in cattle and horses with rabies. Journal of Veterinary Diagnostic Investigation, 28(4), 455-460. https://doi.org/10.1177/1040638716647992

Batista, H. B. C. R., Franco, A. C., \& Roehe, P. M. (2007). Raiva: uma breve revisão. Acta Scientiae Veterinariae, 35(2), 125. https://seer.ufrgs.br/ActaScientiaeVeterinariae/article/view/15959

Belotto, A., Leanes, L. F., Schneider, M. C., Tamayo, H., \& Correa, E. (2005). Overview of rabies in the Americas. Virus Research, 111(1), 5-12. https://doi.org/10.1016/j.virusres.2005.03.006

Bianchi, R. M., Panziera, W., Galiza, G. J. N., Kommers, G. D., \& Fighera, R. A. (2017). Rabies outbreak in buffaloes in Rio Grande do Sul, Brazil. Ciência Rural, 47(4). https://doi.org/10.1590/0103-8478cr20160523

BRASIL. (2009). Controle da Raiva dos Herbívoros. Manual Técnico. Ministério Da Agricultura, Pecuária e Abastecimento, Brasília, Distrito Federal.

BRASIL. (2016). Manual de vigilância, prevenção e controle de zoonoses: normas técnicas e operacionais [recurso eletrônico]. Ministério Da Saúde. Secretaria de Vigilância Em Saúde. Departamento de Vigilância Das Doenças Transmissíveis. / Departamento de Vigilância Das Doenças Transmissíveis. - Brasília : Ministério Da Saúd.

Carini, A. (1911). Sur une grande épizootie de rage. Ann Inst Pasteur, 25, 843-846.

Casagrande, R. A., Wouters, F., Boabaid, F. M., Antoniassi, N. A. B., Pavarini, S. P., Oliveira, L. G. S., Bandarra, P. M., Zlotowski, P., \& Driemeier, D. (2012). Raiva em bovino associada a intoxicação espontânea por Sida carpinifolia. Ciência Rural, Santa Maria, 42(10), 1872-1875.

Claus, M. P., Alfieri, A. F., \& Alfieri, A. A. (2002). Herpesvírus bovino tipo 5 e meningoencefalite herpética bovina. Semina: Ciências Agrárias, 23(1), 131-141.

FAO. (2017). The Food and Agriculture Organization and Rabies Prevention and Control. Food and Agriculture Organization of the United Nations. http://www.fao.org/3/a-i7873e.pdf

Feng, Y., Wang, W., Guo, J., Alatengheli, Li, Y., Yang, G., Su, N., Zhang, L., Xu, W., Sheng, Z., Ma, L., Gui, J., Dejide, Lin, H., \& Tu, C. (2015). Disease outbreaks caused by steppe-type rabies viruses in China. Epidemiology and Infection, 143(6), 1287-1291. https://doi.org/10.1017/S0950268814001952

Fernandes, C. G., \& Riet-Correa, F. (2007). Raiva. In F. Riet-Correa, S. A.L., L. R.A.A., \& B. J. R. J. (Eds.), Doenças de Ruminantes e Equídeos (pp. 650-656). Gráfica e Editora Pallotti.

Filho, F. A., Brasileiro, F. C. S., Guedes, P. E. B., \& Michel, A. F. R. M. (2016). Aspectos clínicos e patológicos da raiva em ovino-Relato de caso. Brazilian Journal of Veterinary Medicine, 38(3), 222226.

Heinemann, M. B., Fernandes-Matioli, F. M. C., Cortez, A., Soares, R. M., Sakamoto, S. M., Bernardi, F., Ito, F. H., Madeira, A. M. B. N., \& Richtzenhain, L. J. (2002). Genealogical analyses of rabies virus strains from Brazil based on $\mathrm{N}$ gene alleles. Epidemiology and Infection, 128(3), 503-511. https://doi.org/10.1017/S095026880200688X

Ito, M., Arai, Y. T., Itou, T., Sakai, T., Ito, F. H., Takasaki, T., \& Kurane, I. (2001). Genetic characterization and geographic distribution of rabies virus isolates in Brazil: identification of two reservoirs, dogs and vampire bats. Virology, 284(2), 214-222.

Jiang, Y., Yu, X., Wang, L., Lu, Z., Liu, H., Xuan, H., Hu, Z., \& Tu, C. (2008). An outbreak of pig rabies in Hunan province, China. Epidemiology and Infection, 136(4), 504-508. https://doi.org/10.1017/S0950268807008874

Kanitz, F. A., Cargnelutti, J. F., Weiblen, R., Batista, H. B. C. R., \& Flores, E. F. (2015). Virus isolation 
in cell culture for confirmatory diagnostic of rabies in bovine specimens. Ciência Rural, 45(12), 2193-2196. https://doi.org/10.1590/0103-8478cr20141690

Langohr, I. M., Irigoyen, L. F., Lemos, R. A. A., \& Barros, C. S. L. (2003). Aspectos epidemiológicos, clínicos e distribuição das lesões histológicas no encéfalo de bovinos com raiva. Ciência Rural, Santa Maria, 33(1), 125-131.

Lemos, R. A. A., Driemeier, D., Guimarães, E. B., Dutra, I. S., Mori, A. E., \& Barros, C. S. L. (2004). Lead poisoning in cattle grazing pasture contaminated by industrial waste. Veterinary and Human Toxicology, 46(6), 326-328. http://www.ncbi.nlm.nih.gov/pubmed/15587252

Lima, E. F., Riet-Correa, F., Castro, R. S., Gomes, A. A. B., \& Lima, F. S. (2005). Sinais clínicos, distribuição das lesões no sistema nervoso e epidemiologia da raiva em herbívoros na região Nordeste do Brasil. Pesquisa Veterinária Brasileira, 25(4), 250-264.

Marcolongo-Pereira, C., Sallis, E. S. ., Grecco, F. B., Raffi, M. B., Soares, M. P., \& Schild, A. L. (2011). Raiva em bovinos na Região Sul do Rio Grande do Sul: epidemiologia e diagnóstico imunohistoquímico. Pesquisa Veterinária Brasileira, 31(4), 331-335. https://doi.org/10.1590/S0100$\underline{736 \times 2011000400010}$

Mello, A. K. M., Brumatti, R. C., Neves, D. A., Alcântara, L. O. B., Araújo, F. S., Gaspar, A. O., \& Lemos, R. A. A. (2019). Bovine rabies: economic loss and its mitigation through antirabies vaccination. Pesquisa Veterinária Brasileira, 39(3), 179-185. https://doi.org/10.1590/1678-5150pvb-6201

Morais, R. M., Wicpolt, N. S., Molossi, F. A., Ogliari, D., Mori, A. M., Surkamp, V., \& Gava, A. (2019). Neurological diseases in cattle caused by plants and mycotoxins in Santa Catarina state, Brazil. Pesquisa Veterinária Brasileira, 39(4), 244-250. https://doi.org/10.1590/1678-5150-pvb-6024

Nair, R. P., \& Jayson, E. A. (2020). Wild Pig Rabies-A Case Study From Pathippara, Malappuram, Kerala. Journal Homepage, 6(2).

Oliveira, A. N., Andrade, M. C. R., Silva, M. V., Moura, W. C., \& Cortez Contreiras, E. (2000). Immune response in cattle vaccinated against rabies. Memórias Do Instituto Oswaldo Cruz, 95(1), 83-88. https://doi.org/10.1590/S0074-02762000000100013

Oliveira, P. A., Alves, D. M., Zamboni, R., Scheid, H. V., Alberti, T. S., Marcolongo-Pereira, C., Schild, A. L., \& Sallis, E. S. V. (2018). Babesiose cerebral em bezerros. Pesquisa Veterinária Brasileira, 38(5), 832-834. https://doi.org/10.1590/1678-5150-pvb-5424

Pedroso, P. M. O., Colodel, E. M., Gomes, D. C., Varaschin, M. S., Bezerra Júnior, P. S., Barbosa, J. D., Tokarnia, C. H., \& Driemeier, D. (2010). Aspectos clínico-patológicos e imuno-histoquímicos de equídeos infectados pelo vírus da raiva. Pesquisa Veterinária Brasileira, 30(11), 909-914.

Pedroso, P. M. O., Colodel, E. M., Pescador, C. A., Arruda, L. P., \& Driemeier, D. (2009). Aspectos clínicos e patológicos em bovinos afetados por raiva com especial referência ao mapeamento do antígeno rábico por imuno-histoquímica. Pesquisa Veterinária Brasileira, 29(11), 899-904. https://doi.org/10.1590/S0100-736X2009001100006

Peixoto, P. V. (1998). Raiva bovina e linhas de conduta. Pesquisa Veterinária Brasileira, Rio de Janeiro, v. 18 n.1, p.45-46.

Pessoa, C. R. M., Silva, M. L. C. R., Gomes, A. A. B., Garcia, A. I. E., Ito, F. H., Brandão, P. E., \& Riet-Correa, F. (2011). Paralytic rabies in swine. Brazilian Journal of Microbiology, 42(1), 298-302. https://doi.org/10.1590/S1517-83822011000100038

Picard-Meyer, E., Garam, C. P., Schereffer, J. L., Robardet, E., \& Cliquet, F. (2019). Evaluation of six TaqMan RT-rtPCR kits on two thermocyclers for the reliable detection of rabies virus RNA. Journal of Veterinary Diagnostic Investigation, 31(1), 47-57. https://doi.org/10.1177/1040638718818223

Rech, R. R., Fighera, R. A., Oliveira, F. N., \& Barros, C. S. L. (2004). Meningoencefalite granulomatosa em bovinos em pastoreio de ervilhaca (Vicia spp). Pesquisa Veterinária Brasileira, 24(3), 169-172. https://doi.org/10.1590/S0100-736X2004000300010

Rissi, D. R., Pierezan, F., Kommers, G. D., \& Barros, C. S. L. (2008). Ocorrência de raiva em ovinos no Rio Grande do Sul. Pesquisa Veterinária Brasileira, 28(10), 495-500. https://doi.org/10.1590/S0100-736X2008001000009 
Rodriguez, L. L., Roehe, P. M., Batista, H., \& Kurath, G. (2007). Rhabdoviridae. Virologia Veterinária. UFSM, Santa Maria, 691-718.

Sanches, A. W. D., Langohr, I. M., Stigger, A. L., \& Barros, C. S. L. (2000). Doenças do sistema nervoso central em bovinos no Sul do Brasil. Pesquisa Veterinária Brasileira, 20(3), 113-118. https://doi.org/10.1590/S0100-736X2000000300005

Santos, B. L., Marcolongo-Pereira, C., Stigger, A. L., Coelho, A. C. B., Soares, M. P., Sallis, E. S. V, Barreto, F., \& Schild, A. L. (2014). Misuse of organophosphate: potential risk to cattle in Southern Brazil. Pesquisa Veterinária Brasileira, 34(7), 655-658.

SIB. (2020). Swiss Institute of Bioinformatics. https://viralzone.expasy.org/22?outline=all_by_species

Siepker, C. L., Dalton, M. F., McHale, B. J., Sakamoto, K., \& Rissi, D. R. (2020). Neuropathology and diagnostic features of rabies in a litter of piglets, with a brief review of the literature. Journal of Veterinary Diagnostic Investigation, 32(1), 166-168. https://doi.org/10.1177/1040638719898687

Terra, J. P., Blume, G. R., Rabelo, R. E., Medeiros, J. T., Rocha, C. G. N., Chagas, I. N., Aguiar, M. da S., \& Sant'Ana, F. J. F. de. (2018). Neurological diseases of cattle in the state of Goiás, Brazil (20102017). Pesquisa Veterinária Brasileira, 38(9), 1752-1760. https://doi.org/10.1590/1678-5150-pvb$\underline{5768}$

Tolouei, M., \& Mostofi, S. (2017). A case report of Rabies in a horse in Tabriz, Iran. Journal of Zoonotic Diseases, 2(1), 35-42.

Verdes, J. M., Sant'Ana, F. J. F., Sabalsagaray, M. J., Okada, K., Calliari, A., Moraña, J. A., \& Barros, C. S. L. (2016). Calbindin D28k distribution in neurons and reactive gliosis in cerebellar cortex of natural Rabies virus -infected cattle. Journal of Veterinary Diagnostic Investigation, 28(4), 361368. https://doi.org/10.1177/1040638716644485

WHO, FAO, \& OIE. (2019). First annual progress report: Global Strategic Plan to End Human Deaths from Dog-mediated Rabies by 2030. World Health Organization (WHO), Food and Agriculture Organization of the United Nations (FAO) and World Organisation for Animal Health (OIE).

Wright, A. D., \& Greene, E. A. (2016). Rabies in Arizona: Equine Risk and Prevention. College of Agriculture, University of Arizona (Tucson, AZ).

Zhu, Y., Zhang, G., Shao, M., Lei, Y., Jiang, Y., \& Tu, C. (2011). An outbreak of sheep rabies in Shanxi province, China. Epidemiology and Infection, 139(10), 1453-1456. https://doi.org/10.1017/S0950268811001348

Recebido: 8 de junho, 2020 Aprovado: 9 de julho, 2020

Disponível online: 23 de outubro, 2020
Licenciamento: Este artigo é publicado na modalidade Acesso Aberto sob a licença Creative Commons Atribuição 4.0 (CC-BY 4.0), a qual permite uso irrestrito, distribuição, reprodução em qualquer meio, desde que o autor e a fonte sejam devidamente creditados. 